\title{
Evaluation of the benefit of using a combination of autologous platelet rich-plasma and hyaluronic acid for the treatment of Peyronie's disease
}

\author{
Ronald Virag $^{1 *}$, Hélène Sussman ${ }^{1}$, Sandrine Lambion ${ }^{2}$ and Valérie de Fourmestraux ${ }^{3}$ \\ ${ }^{1}$ Centre d'Exploration et Traitement de l'Impuissance (CETI) Paris, France \\ ${ }^{2} \mathrm{SLC}$ Besançon, France \\ ${ }^{3}$ Regenlab SA, Switzerland
}

\begin{abstract}
Background: Platelet-Rich Plasma (PRP) has been successfully used for different medical conditions, to help regenerate fibrotic or inflammatory tissues. Peyronie's disease (PD) could be a target for such treatment. In this study, PRP in combination with hyaluronic acid (HA) is proposed as an innovative treatment for this condition.

Objectives: To assess the effects of repeated intralesional injections inside the tunica albuginea (TA) with a combination of PRP and HA in PD patients.

Design, setting, and participants: 90 patients, naive of any prior interventional treatment, were injected with $8 \mathrm{ml}$ of PRP combined with HA directly in the diseased area of TA under ultrasound (US) guidance. Injections were repeated 4 times within 2 months. Additional monthly sessions were done, if necessary.

Outcome measurements and statistical analysis: Penile deformation, TA thickening, presence and size of calcifications, and questionnaires evaluating both PD and sexual function. Global results were classified into satisfactory improvement (I+) unsatisfactory (I-) and unchanged (U).

Results and limitations: Angulation and thickening were both significantly improved after 4 sessions and continuously improved with the number of sessions, to achieve a mean final improvement of $39.65+/-24.83 \%$ (p<0.001) (CI 14.26;18.82) and 26.23+/-10.29\% (p<0.001) (CI 0.99;1.22), respectively . Younger patients achieved better results. $73.3 \%$ of the patients belonged to I+ group; $67.8 \%$ felt an improvement, $62.2 \%$ a decrease of their deformation, $46.7 \%$ had easier sexual intercourses and $70 \%$ judged the treatment as positive. Limitations included the absence of a control group.
\end{abstract}

Conclusions: Repeated intralesional injections of PRP-HA improve significantly penile deformation and thickening of the TA. This fully natural treatment may stand as a first line treatment of PD.

Patient summary: We evaluated here an innovative treatment of Peyronie's disease using intralesional injections of Platelet-Rich Plasma mixed with hyaluronic acid. We observed a significant improvement of the deformation in $70 \%$ of the cases without any serious adverse events.

\section{Introduction}

The treatment of penile deformities first described in 1743 by King Louis XV's first surgeon François Gigot de Lapeyronie [1] has gained much interest especially for non-surgical procedures [2]. An increasing knowledge of the pathophysiology [3] of the disease has urged clinical researchers to propose intralesional treatments [4] such as verapamil [5] and interferon alpha 2B [6] which remain off label, or collagenase clostridium histolycum (CCH) ( Xiapex) which obtained an FDA approval [7] for Peyronie's disease (PD). The interesting improvement rates observed with these treatments are challenged by side effects such as corporeal ruptures for $\mathrm{CCH}$, flu-like symptoms for interferon alpha $2 \mathrm{~B}$, or penile bruising, dizziness and nausea for verapamil.

Moreover, a wider use of Xiapex ${ }^{\circ}$ is to date limited by the high cost of the compound. More recently, Hyaluronic Acid (HA) (7) and Botulinum toxin [8] have also been proposed with the purpose of counteracting tunica fibrosis, the final issue of the pathological process of PD, before the deposit of calcifications [4]. We hypothesized that regenerative medicine could help stop the process and restore function. Although stem cell therapy for erectile dysfunction (ED) [9] and PD
[10] has become a wide subject of research in animal studies with rising hopes for future treatments with adipose derived stem cells (ADSC's), we did not find in the literature any mention of the potential use of autologous platelet-rich plasma (PRP) in both ED and PD. PRP is prepared from autologous blood after centrifugation with an adequate medic al device giving a plasma with a higher platelet concentration than baseline. [VDF2] PRP is a source of platelets growth factors (GFs). In situ activation of platelets induces the orchestrated release of several growth factors such as FGF(fibroblast growth factor), PGDF (platelet-derived growth factor), IGF (insulin-like growth factor), VEGF (vascular endothelial growth factor), and TGF-b (transforming growth factor) [11]. Platelet GFs are signals that regulate cell growth and division, as well as synthesis of extracellular matrix for tissue regeneration. On the other hand, plasma is a source of proteins such as fibrinogen, vitronectin and fibronectin which play a key role in the

Correspondence to: Ronald Virag MD, Centre d'Exploration et Traitement de l'Impuissance (CETI) Paris, France, E-mail : rvirag@wanadoo.fr

Received: June 11, 2017; Accepted: July 05, 2017; Published: July 08, 2017 
regulation of cell-cell interaction and cell spatial organization [12]. Autologous PRP has been widely and safely used in many disciplines including orthopaedics, maxillofacial surgery, plastic and reconstructive surgery [13]. Adding thrombin to PRP produces a platelet gel which can be used as biological glue. One of us (RV) has been using it during graft procedures for PD surgery (unpublished data). From these early experiences, we became interested in an intralesional non-surgical use of PRP for PD. Okabe et al. [13] have shown experimentally that the addition of HA to PRP enhanced its regenerative potential, acting as a biological scaffold. The combination of PRP and HA, now facilitated by the availability of the new medical device CellularMatrix, encouraged us to conduct a first trial on 13 patients with PD [14]. Preliminary data from this case series indicated that patients experienced a significant improvement of their condition, both functionally and anatomically.

Stimulated by these early encouraging results, we designed a new study using extensive clinical (the Peyronie's disease questionnaire PDQ), echographic and photographic assessments as outcome measures in 90 patients whose results we report here are, to the best of our knowledge, the first in the English literature.

\section{Patients and methods}

Between July 2014 and November 2016, 90 patients (aged 25 to 77y, median 56) complaining of penile deformations and/or curvatures linked to the presence of plaques palpated in the tunica albuginea (TA), and who had not received any previous local treatment were enrolled in this study. All patients gave written informed consent.

\section{Patient's evaluation criteria}

Patient's eligibility was assessed on the basis of the onset and duration of the disease, initial local trauma, and presence of ED assessed by the IIEF-5 [15].PDQ questionnaires [16] evaluate symptom's bother. Deformation, consisting of curvatures (angulation in degrees) and/or shaft strictures was measured on photographs of fully erected penis [7].

Duplex ultrasound (DUS) (General Electric Logic F8 with an L12 RS probe) measurements of the thickening of the TA and presence of calcifications were assessed by one of us (HS) with a fixed protocol at each session of treatment (see appendix 1). In addition, patients responded to a self-administered questionnaire.

\section{Treatment protocol}

It is an office procedure under a 3-step penile local anesthesia: suprapubic application of lidocaine and prilocaine (EMLA, Astra Zeneca) 20 minutes prior to the procedure; - penile block with 10 $\mathrm{ml}$ of $2 \%$ lidocaine; - additional local application of a cream mixing lidocaine, tetracaine and tetracaine hydrochloride (Receptura Apotheke Germany) on the injection sites. Four $\mathrm{ml}$ of PRP and $4 \mathrm{ml}$ of a combination of PRP/HA were prepared with a Regen BCT tube and a BCT HA tube (Regen Lab SA, Switzerland). Autologous venous blood was collected in both tubes and centrifuged for 5 minutes at $1500 \mathrm{~g}$. At the end of the centrifugation, red blood cells were trapped under a separator gel, while platelets were settled on its surface. After appropriate resuspension of platelets in plasma, both preparations were collected in a syringe and mixed together. Eight $\mathrm{ml}$ of this preparation (containing $6 \mathrm{ml}$ of PRP and $2 \mathrm{ml}$ of HA) were injected into the TA's diseased sites under DUS control (Figure 1). Prior to injections, mechanical action was applied to the fibrotic and/or calcified plaques with $22 \mathrm{G}$ and/or $18 \mathrm{G}$ needles (BD Microlance ${ }^{\mathrm{ma}} 3$ ). At the end of the procedure, a slightly compressive dressing was applied. Intercourse was prohibited for 48 hours. Injections were repeated 4 times every 15 days. A first evaluation took place 3 months after the first treatment session. According to the outcomes, two additional sessions were scheduled monthly, and repeated each three months, if necessary. All patients had at least 5 sessions.

\section{Main outcomes measures}

Co-primary endpoints consisted of the percent changes in penile curvature and/or deformity, and in maximum thickness, between baseline and one month after the fourth treatment session and after a variable additional sessions (mean 7).The co-primary endpoints were assessed both globally and according to the severity of deformation (below $30^{\circ}$, between $30^{\circ}$ and $59^{\circ}$ and over) and the presence or not of calcifications (Table 1).

Secondary endpoints were the changes in the 3 domains of the PDQ and the IIEF-5 and answers to a self-administered 5-item questionnaire evaluating treatment efficacy, deformation, erection, sexual intercourse and global assessment of the treatment (for details, see appendix 3) .

Age, trauma during intercourse, PD duration, number of treatment sessions were tested as possible parameters influencing the results. By grouping these data, we could finally classify the results into 3 groups: I+satisfactory improvement $(\mathrm{n}=66)$ I-unsatisfactory improved $(\mathrm{n}=11)$ and bad B ( $n=13)$ according to the decrease of angulation, thickening and scores achieved by the self-administered questionnaire.

\section{Statistical analysis}

Statistical analysis was performed using SPSS 18.0 for Windows.

One-sample paired $t$ test was used to compare the within-group change in penile curvature and/or deformity and in maximum thickness (change versus baseline).

The changes in the 3 domains of the PDQ, the IIEF- 5 and answers to the self-administered questionnaire were studied by one-sample paired $\mathrm{t}$ test.

The results were evaluated in relation to age, trauma during intercourse, PD duration, number of treatment sessions, and presence of calcifications using a Chi-square test.

\section{Results}

Average duration of the disease was $20.8+/-19.2$ months. 84 patients suffered from a mean curvature of the penis of $44.37+/$ $15.93^{\circ}$ and 4 had an isolated stricture of the shaft, while 7 had both deformations. For $13.3 \%$ of the patients, angulation was below $30^{\circ}$; for $68.9 \%$ of them, it was between $30^{\circ}$ and $59^{\circ}$, and for $13.3 \%$ of them it was over $59^{\circ}$. ED was present prior to PD onset in $34.4 \%$ of the patients. The maximum average thickening was $4.14+/-0.8 \mathrm{~mm}$. All but six PD's plaques (three lateral, 2 ventral and one septal) were localized in the dorsum of the TA. Calcifications were present in $31.3 \%$ of the patients $(\mathrm{n}=28)$. A direct trauma to the penis was reported by15 patients (16.7\%). Dupuytren's disease (2 cases) and ankylosing spondylitis (2 cases) were also recorded. Average number of treatment sessions was $7.09+/-2.54$.

Both deformation and thickening of the TA one month after 4 sessions $(n=84)$ and at the last follow-up visit $(n=54)$ showed a significant decrease (Table 1). The mean final improvement was respectively $16.54+/-10.51^{\circ}$ and $1.11+/-0.52 \mathrm{~mm}$ with a mean gain percentage of $39.65+/-24.83 \%$ and $26.22+/-10.29 \%$ (Table $1)$. Presence of calcifications $(n=28)$ did not change significantly the results but 6 patients (21.4\%) experienced a decrease of their US density (Figure2). These improvements were already significant after 4 sessions 
Virag R (2017) Evaluation of the benefit of using a combination of autologous platelet rich-plasma and hyaluronic acid for the treatment of Peyronie's disease

Table 1. Percent change in penile curvature and/or deformity and thickness between baseline and after the fourth treatment and additional treatment sessions globally and according to the severity of deformation and the presence or not of calcifications

\begin{tabular}{|c|c|c|c|c|c|}
\hline \multirow{2}{*}{\multicolumn{2}{|c|}{$\begin{array}{l}\text { Angulation (after the fourth treatment } \\
\text { session) }\end{array}$}} & Mean & SD & $P$ value & CI \\
\hline & & 279970 & 2101525 & $\mathrm{P}<0.001$ & $9.74 ; 14.55$ \\
\hline \multicolumn{2}{|c|}{$\begin{array}{c}\text { Angulation (additional treatment } \\
\text { sessions) }\end{array}$} & 396546 & 2483378 & $\mathrm{P}<0.001$ & $14.26 ; 18.82$ \\
\hline \multicolumn{2}{|c|}{$\begin{array}{l}\text { Thickness (after the fourth treatment } \\
\text { session) }\end{array}$} & 183582 & 910997 & $\mathrm{P}<0.001$ & $0.67 ; 0.86$ \\
\hline \multicolumn{2}{|c|}{$\begin{array}{c}\text { Thickness (additional treatment } \\
\text { sessions) }\end{array}$} & 262276 & 1029582 & $\mathrm{P}<0.001$ & $0.99 ; 1.22$ \\
\hline \multicolumn{2}{|c|}{ Presence or not of calcifications } & $\begin{array}{c}\text { Thickness (after the fourth } \\
\text { treatment session) }\end{array}$ & $\begin{array}{c}\text { Thickness (additional treatment } \\
\text { sessions) }\end{array}$ & $\begin{array}{l}\text { Angulation (after the fourth } \\
\text { treatment session) }\end{array}$ & $\begin{array}{c}\text { Angulation (additional } \\
\text { treatment sessions) }\end{array}$ \\
\hline \multirow[t]{3}{*}{ No } & Mean & 188264 & 274160 & 298156 & 435948 \\
\hline & SD & 923874 & 1013316 & 1986978 & 2473753 \\
\hline & $P$ value & & & & \\
\hline \multirow{3}{*}{ Yes } & Mean & 173382 & 234850 & 236779 & 308650 \\
\hline & SD & 890173 & 1033799 & 2339249 & 2336245 \\
\hline & $P$ value & & & & \\
\hline \multicolumn{2}{|c|}{ Severity of deformation } & $\begin{array}{c}\text { Thickness (after the fourth } \\
\text { treatment session) }\end{array}$ & $\begin{array}{c}\text { Thickness (additional treatment } \\
\text { sessions) }\end{array}$ & $\begin{array}{l}\text { Angulation (after the fourth } \\
\text { treatment session) }\end{array}$ & $\begin{array}{c}\text { Angulation (additional } \\
\text { treatment sessions) }\end{array}$ \\
\hline \multirow[t]{2}{*}{ Below $30^{\circ}$} & Mean & 215625 & 270283 & 296936 & 504425 \\
\hline & SD & 951791 & 1159128 & 1899753 & 3171063 \\
\hline \multirow{2}{*}{$\begin{array}{l}\text { Between } 30^{\circ} \\
\text { and } 59^{\circ}\end{array}$} & Mean & 192361 & 272862 & 284790 & 384166 \\
\hline & SD & 857144 & 904433 & 2203684 & 2439523 \\
\hline \multirow[t]{2}{*}{ Over 59} & Mean & 131058 & 217283 & 237155 & 347518 \\
\hline & SD & 910650 & 1335961 & 1819088 & 1706414 \\
\hline
\end{tabular}
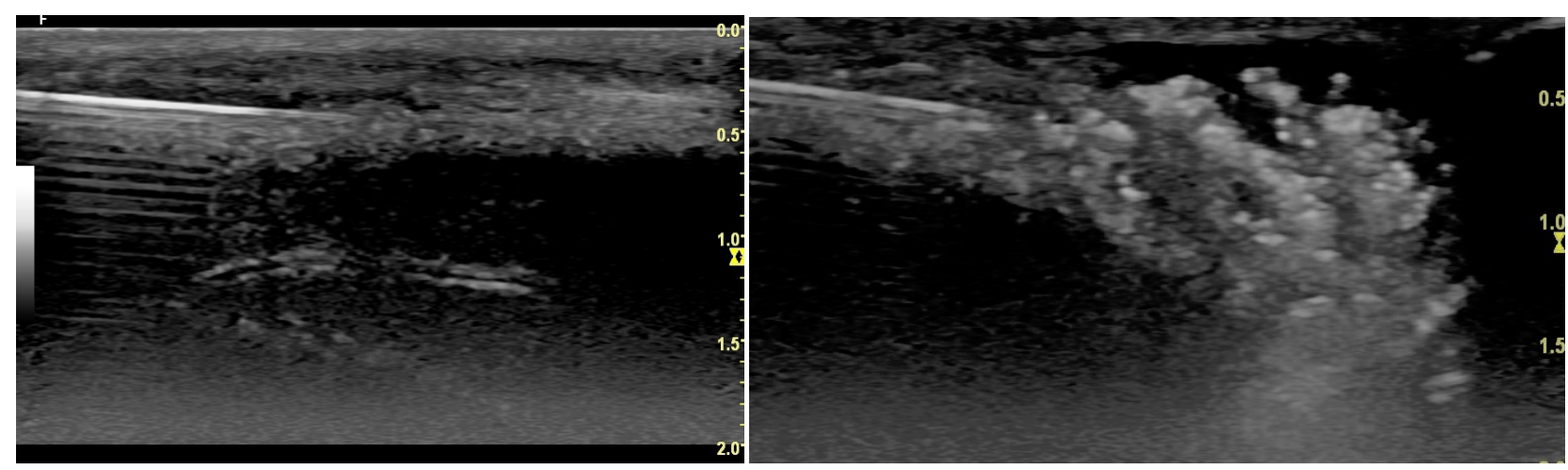

Figure 1. A: Longitudinal view of the dorsal TA and below cavernous body with one artery. In white the needle inserted in the fibrotic TA. B: Imaging of the injection of autologous PRP-HA
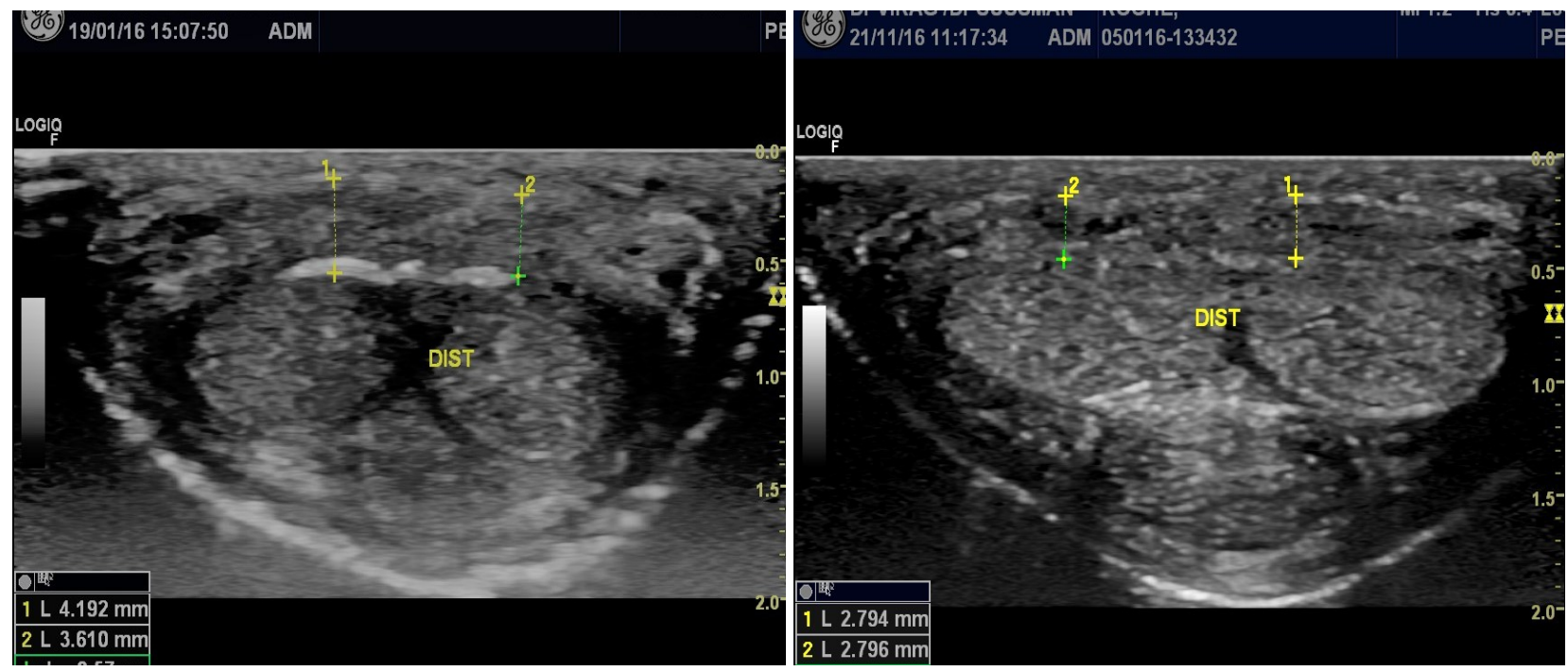

Figure 2. Distal Transversal echographic image of dorsal TA in 37 year old patient with PD. A: Initial evaluation. Dorsal TA thickness between 3.6 and $4.2 \mathrm{~mm}$ with a calcified plaque of the deep layer of TA. B: 10 months later after 10 sessions of PRP-HA : decrease of the average thickening to $2.8 \mathrm{~mm}$ and the calcified plaque has almost completely disappeared 
$(\mathrm{p}<0.001)$ and increased with the number of sessions $(\mathrm{p}<0.001)$. The three domains of the PDQ questionnaire showed significant changes (Figure 2). Considering only patients suffering from ED prior to the onset of PD $(\mathrm{n}=11)$, IIEF-5 improved significantly $(13.82+/-3.7$ vs $17.91+/-3.2)(\mathrm{p}=0.008)(\mathrm{CI}-6.85 ;-1.33)$. Finally, $62.2 \%$ of the patients felt a decrease in their deformation, $43.3 \%$ judged that their erections were better, $46.7 \%$ thought that sexual activity was easier and $67.8 \%$ considered that the treatment improved their initial condition. Only one patient stopped the treatment after 4 sessions because of worsening symptoms and was offered surgery. At the end, $73.3 \%$ of the patients belonged to group I with satisfactory results, $12.2 \%$ to group II with unsatisfactory results and $14.4 \%$ to group III, classified as bad results. In addition, the influence of several factors such as the age, severity of initial angulation and thickening, duration of PD and presence of trauma on the outcomes was also tested. It appears that the number of sessions was higher in Group I (7.32 vs 6.18 and 6.11 for Group I, II and III, respectively). In Group I, mean basic angulation and thickening were lower. Decrease of TA thickening was significantly correlated to the age $(\mathrm{p}=0.026)$. It was also found a positive correlation between the decrease of angulation (\%) and the TA thickening, after 4 sessions $(p=0.015)$ and at the end of treatment $(p=0.011)$. Neither duration of $\mathrm{PD}$, nor the presence of direct trauma had significant influence on the outcomes.

\section{Complications}

Ecchymosis was present in $16.7 \%$ of the patients and marked hematoma in $10 \%$.

Two patients suffered from transient hypotension after local anaesthesia.

No serious adverse events were recorded.

\section{Discussion}

This study on 90 patients confirms the positive initial conclusions of our preliminary trial [14]. Objective endpoints collected one month after 4 sessions and at the end of an average of 3 to 5 additional sessions showed significant improvement of $\mathrm{PD}$, assessed by the 3 domains of the PDQ questionnaire, as well as by the responses to an additional self-administered questionnaire and to the IIEF-5 (Figure 3). We achieved a mean reduction of the angle of $16.54^{\circ}$, which represents an average reduction of $39.65 \%$. These results were even better -while non-significant, due to an insufficient number of cases- for the group of patients without calcifications $\left(18.07+/-10.89^{\circ}\right.$, corresponding to a reduction of $43.59 \%)$.

According to current regulations, PRP must be prepared from fresh blood and used during the same medical session and in the same room (extemporaneous procedure), making it difficult to set-up placebocontrolled studies. Nevertheless, available previous placebo -controlled studies [7] show a maximum angle reduction of $21 \%$ with Impress I and of $15.2 \%$ for the placebo group. Furthermore, the comparison of our results with those of untreated patients, as in Berookhim's trial [17] conducted on 176 patients to study the natural history of PD in the absence of medical or surgical therapy, further supports a beneficial effect of the combination of PRP and HA, as only $12 \%$ of untreated patients had an improvement of their deformation vs $62 \%$ in the present study.

A comparison of our data with other intralesional injection trials, especially both Impress I and II series of the Xiapex trial [7], shows slightly better results, particularly if only the patients without calcifications as those enrolled in the Xiapex trial are considered (Figure 4). Moreover, contrary to Xiapex ${ }^{\circ}$ [18], where it seems that after three cycles of treatment there is no more improvement, addition of sessions of PRP combined with HA after the first cycle of four, improves the results. The reason might lie in the biological process induced by the combination of PRP and HA. Contrary to $\mathrm{CCH}$, which main aim is to destroy the plaque, PRP combined with HA is expected to restore normal tissue after digging of small tunnels into TA's fibrotic tissue with a needle (see below). HA alone has been shown to be active on PD in a placebo-controlled study [8]. Preliminary data seems to indicate that a combination of PRP and HA provides better outcomes than HA alone for the treatment of gonarthrosis $[19,20]$ and wound defects $[21,22]$. PRP and HA are also expected to increase the potential

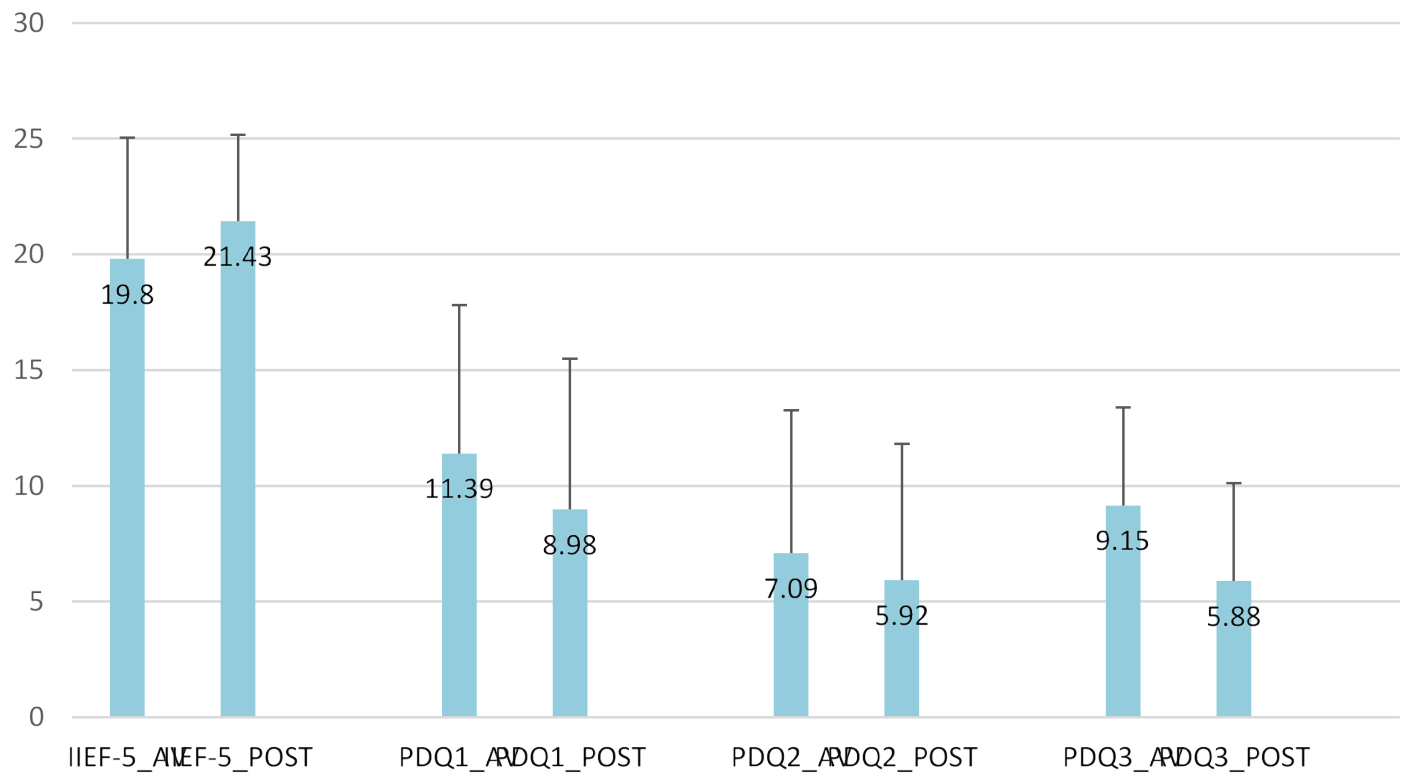

Figure 3. Comparison of IIEF-5 (baseline and of study visit) and PDQ questionnaire results (before and after each visit). The results showed significant difference in mean PDQ questionnaire in PDQ1 with $\mathrm{p}=0.002$ (CI 0.720;2.968), PDQ2 with $\mathrm{p}=0.021$ (CI 0.275;3.225) and PDQ3 with $\mathrm{p}<0.001$ (CI 1.520;3.220). 
60

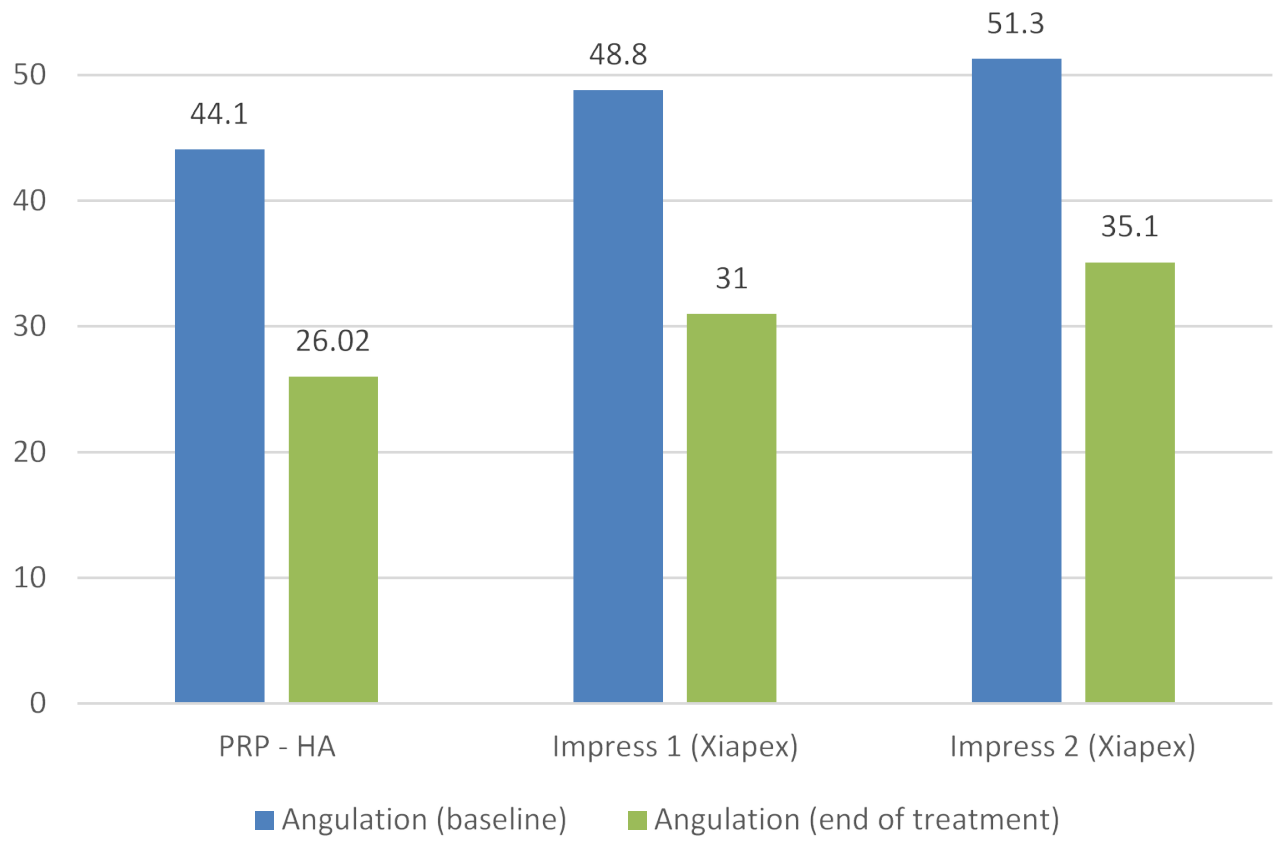

Figure 4. Mean angulation measured in degrees before treatment and at the end of the study with PRP-HA and Xiapex (Impress 1 and Impress 2 (7)).

efficacy of stem cells, as suggested by in vitro and animal studies $[13,23]$. PRP rich in growth factors and other compounds initiates a reconstructive process in TA, whose global effects are visible through echographic controls. Although widely used for diagnostic purpose $[24,25]$, US technique is very specific to this proposed technique of treatment with two advantages. First, it allows taking precise measurements of the whole albuginea, providing comparison data all along the procedure. From this, we have learned that the diseased TA extends largely beyond what is manually palpated, and also that the reduction of the thickening precedes the decrease of angulation, while both are correlated $(\mathrm{p}=0.015$ after 4 sessions and $\mathrm{p}=0.011$ at the end of each patient's treatment). Second, injections under US control are much more precise and safer. They also allow applying a mechanical action on the heavily fibrotic and/or calcified areas. Needles are used to dig channels into the fibrotic layers before injecting PRP and HA. Imaging avoids any major complications such as tunica ruptures or intracavernous injection of the product (Figure B in appendix 4), which have been reported with Xiapex [26]. Complications were limited to transient ecchymosis even in patients under anticoagulant treatment. Based on the use of autologous blood extemporaneously processed, the combination of PRP and HA is an office treatment complying with all regulations concerning fresh blood manipulations. It is economically viable, being much cheaper than Xiapex and Interferon alpha. Patients' satisfaction, whatever measurements are used to quote it, was very high. Interestingly, patients themselves, even if the results were not tangible, asked to continue the treatment.

If confirmed in larger controlled studies, the use of a combination of PRP and HA obtained with CellularMatrix BCT-HA and Regen BCT devices for PD will stand as the first autologous blood-based treatment used for a sexual dysfunction. We are currently planning a similar study aiming at assessing the improvement of ED, based on the fact that $37 \%$ of the patients of the present study claimed better erections, independently of the improvement of PD symptoms.

\section{References}

1. Gigot de Lapeyronie F. De quelques obstacles qui s'opposent à l'éjaculation naturelle de la semence. Mémoires de l'Académie Royale de Chirurgie $1761 ; 1$ : 425-434

2. Joice GA, Burnett AL (2016) Nonsurgical Interventions for Peyronie's Disease: Update as of 2016. World J Mens Health 34: 65-72. [Crossref]

3. Al-Takhafi S, Al-Hatal N (2016) Peyronie's disease: a literature review on epidemiology, genetics, pathophysiology, diagnosis and work -up. Transl Andol Urol 5: 280-289 [Crossref]

4. Chong W, Tan RB1 (2016) Injectable therapy for Peyronie's disease. Transl Androl Urol 5: 310-317. [Crossref]

5. Levine LA, Costabile RA (2012) Is intralesional verapamil effective therapy for Peyronie's disease? J Urol 188: 704-706. [Crossref]

6. Milam DF (2015) Intralesional Interferon- $\hat{I} \pm 2 b$ Improves Penile Curvature in Peyronie's Disease. J Urol 194: 1533. [Crossref]

7. Levine LA, Cuzin B, Mark S, Gelbard MK, Jones NA et al. (2015) Clinical safety and effectivenessof Collagenase Clostridium Histolyticum injection in patients with Peyronie's disease A phase 3 Open-Label study. J Sex Med 12: 248-258 [Crossref]

8. Zucchi A, Costantini E, Cai T, Cavallini G, Liguori G et al. (2016) Intralesional injection of hyaluronic acid in patients affected with Peyronies disease : Preliminary results from a prospective multicenter pilot study. Sex Med $4: 85-90$ [Crossref]

9. Khera M. Clinical Trials.Gov H22411 Botox for Peyronie's disease

10. Ching-Shwum L, Zhong-Cheng X, Wang Z, Deng C, Huang YC, Lin G et al. (2012) Stem Cell therapy for erectile dysfunction: a critical review. Stem Cells Dev 21: 343351 [Crossref]

11. Atashi F, Serre-Beinier V, Nayernia Z, Pittet-Cuénod B, Modarressi A (2015) Platelet Rich Plasma Promotes Proliferation of Adipose Derived Mesenchymal Stem cells via Activation of AKT and Smad2 Signaling Pathways. J Stem Cell Res Ther 5:8.

12. Linsley C, Wu B, Tawil B (2013) The effect of fibrinogen, collagen type I, and fibronectin on mesenchymal stem cell growth and differentiation into osteoblasts. Tissue Eng Part A 19: 1416-1423. [Crossref]

13. Okabe K, Yamad Y, Ito K, Kohgo T, Yoshimi R et al. (2009) Injectable soft-tissue augmentation and regenerative medicine with human mesenchymal stromal cells, platelet-rich plasma and hyaluronic acid scaffolds. Cytotherapy 11:307-316 [Crossref] 
14. Virag R, Sussman H, Lobel B.A (2014) new treatment of Lapeyronies'disease by local injections of Plasma-rich platelets and Hyaluronic acid. E-mémoires de l'Académie Nationale de Chirurgie. 13: 96-100 (in French- Abstract in English)

15. Rosen RC, Cappelleri JC, Smith MD, Lipsky J, Peña BM (1999) Development and evaluation of an abridged, 5-item version of the International Index of Erectile Function (IIEF-5) as a diagnostic tool for erectile dysfunction. Int J Impot Res. 11:319-26 [Crossref]

16. Hellstrom WJ, Feldman RA, Coyne KS, Kaufman GJ, Smith TM et al. (2015) Selfreport and clinical response to Peyronie's disease treatment : Peyronies's disease questionnaryResults from large double-blind, randomized, placebo-controlled studies. Urology 86: 291-298

17. Berookhim MB, Choi J, Alex B, Mulhall J (2014) Deformity stabilization and improvement in men with untreated Peyronies'disease. BJU international 113:133-136 [Crossref]

18. Anaissie J, Yafi FA, DeLay KJ, Traore EJ, Sikka SC et al. (2017) Impact of Number of Cycles of Collagenase Clostridium Histolyticum on Outcomes in Patients With Peyronie's Disease. Urology 100: 125-130. [Crossref]

19. Renevier JL, Marc JF (2014) Etude pilote d'un dispositif médical intra-articulaire innovant dans la prise en charge de la gonarthrose symptomatique fémoro-tibiale grade II-III radiologique après échec d'un AH. Revue du Rhumatisme 815 : A129

20. Lana JF, Weglein A, Sampson S, Vicente EF, Huber SC et al. (2016) Randomized controlled trial comparing hyaluronic acid, platelet-rich plasma and the combination of both in the treatment of mild to moderate osteoarthritis of the knee. J Stem Cells Regen Med 12:69-78. [Crossref]
21. Cervelli V, Lucarini L, Spallone D, Brinci L, de Angelis B (2010) Use of platelet rich plasma and hyaluronic acid on exposed tendons of the foot and ankle. $J$ Wound Care 19: 186, 188-190. [Crossref]

22. Cervelli V, De Angelis B, Lucarini L, Spallone D, Balzani A et al. (2010) Tissue regeneration by tissue engineering and regenerative medicine with human mesenchymal stromal cells, platelet-rich plasma and hyaluronic acid scaffolds. Advances in skin and wound care $23: 262-272$

23. Vadalà G, Russo F, Musumeci M, D'Este M, Cattani C et al. (2016) A clinically relevant hydrogel based on hyaluronic acid and platelet rich plasma as a carrier for mesenchymal stem cells: rheological and biological characterization. J Orthop Res [Crossref]

24. Chung E, Yan H, De Young L, Brock GB (2012) Penile Doppler sonographic and clinical characteristics in Peyronie's disease and/or erectile dysfunction: an analysis of 1500 men with male sexual dysfunction. BJU Int 110: 1201-1205. [Crossref]

25. Levine L, Rybak J, Corder C, Farrel MR (2013) Peyronie's disease plaque calcificationPrevalence, time to identification and development of a new grading calcification. $J$ Sex Med 10:3121-8 [Crossref]

26. Yafi FA, Anaissie J, Zurawin J, Sikka SC, Hellstro WJ (2016) Results of SMSNA survey regarding complications following intralesional injection therapy with Collagenase Clostridum Histolyticum for Peyronie's disease. J Sex Med 13: 684-9

Copyright: ( 2017 Virag R. This is an open-access article distributed under the terms of the Creative Commons Attribution License, which permits unrestricted use, distribution, and reproduction in any medium, provided the original author and source are credited. 


\section{Appendix 1}

\section{US study of PD}

All measurements were carried out by the same person (HS). Thickness of the TA was measured automatically in the dorsum, laterally and ventrally, not only where the plaques were felt but also at three different levels of the penile shaft: proximal, median and distal. The probe was applied transversally for the dorsal and ventral part of the TA and longitudinally for its lateral part. A previous investigation (yet unpublished) conducted on 50 patients naive of PD provided normative data for the TA (Figure A) useful for the comparison with data recorded in the present study. For better comprehension and statistics, for each patient the maximum thickness was elected in the study. The intralesional treatment was systematically injected under US guidance.

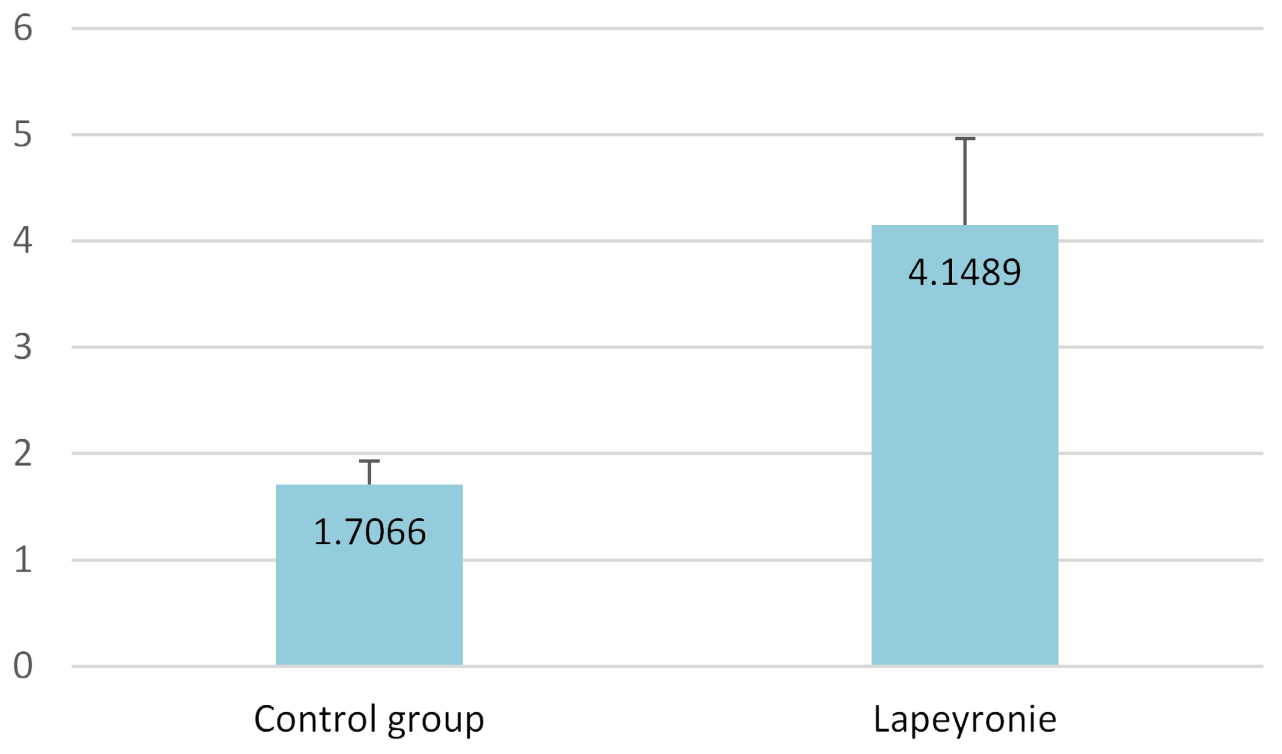

Figure A. Comparison of the average tunica albuginea thickness (in millimeters) between the control group and PD patients

\section{Appendix 2}

A BCT-HA tube (CellularMatrix BCT-HA Kit, Regen Lab SA, Switzerland) and a Regen BCT tube (RegenKit-BCT, Regen Lab SA, Switzerland) were used to prepare a combination of PRP/HA and PRP, respectively. Both tubes are evacuated tubes that contain an anticoagulant solution and an inert thixotropic separating gel that forms a physical barrier between blood components after centrifugation. Additionally, the BCT-HA tube contains $2 \mathrm{ml}$ of a $\%$ hyaluronic acid solution. It is a non-crosslinked hyaluronic acid $(1550 \mathrm{kDa})$ obtained by bacterial fermentation. Once prepared according to the Instructions for Use provided with the kits, both products were collected using a transfer device ensuring a closecircuit preparation procedure and mixed together in a $10 \mathrm{ml}$-syringe. As the Regen Lab's technology allows the preparation of PRP with a platelet concentration 1.6-fold above the value in venous blood, platelet concentration in PRP is expected to be between 300'000 and 350'000 platelets/《l.

\section{Appendix 3}

Additional questionnaire

5 different items were asked after 4 sessions and after the treatment has been completed:

1 - Do you feel cured (5 points) improved (3 points) or unchanged (1)?

2- Has the deformation disappeared (5) diminished (3) or unchanged (1)

3- Is sexual intercourse easier (5) identical (3) or more difficult ( -1)

4- In the overall, do you find the treatment positive (5) or without result (-1)

To obtain the global score mentioned in the text, sum up the scores of the four items

A fifth item was asked in the same questionnaire concerning erections: are they improved, unchanged or worse?

\section{Appendix 4}

Intracavernous accidental injection of Collgenase clostridium histolyticum in a 32Y old patient with Peyronie's disease. Echography one month after intralesional injection (Figure B). 


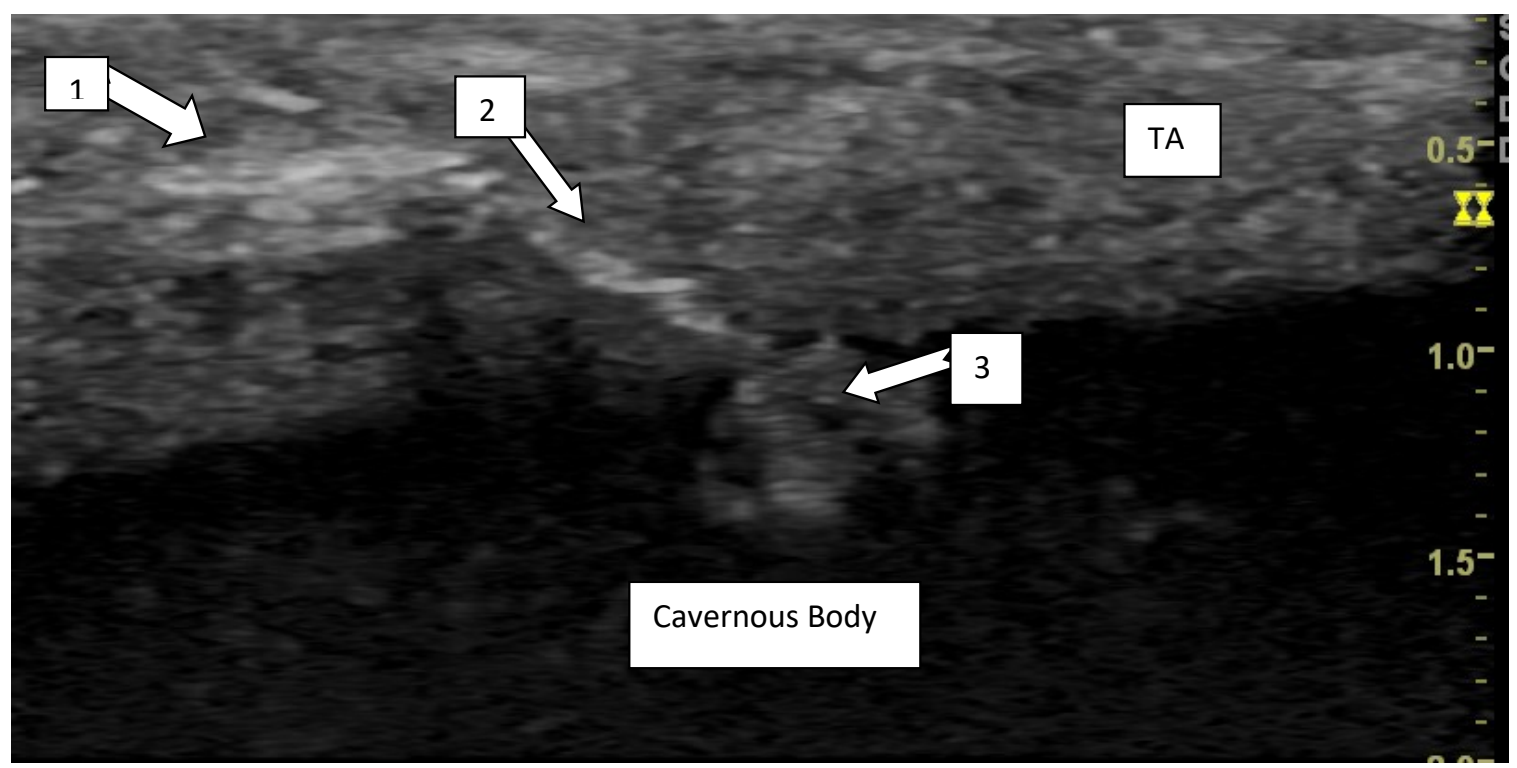

Figure B. 1) Site of CCH injection. 2) Channel inside TA. 3) Accidental Intracavernous injection of CCH 